\title{
Room Temperature Humidity Sensor Based on Single $\beta$-Ga2O3 Nanowires ${ }^{\dagger}$
}

\author{
Guillem Domènech-Gil 1,2,*, Irmina Peiró ${ }^{1}$, Elena López-Aymerich ${ }^{1}$, Mauricio Moreno 1,2, \\ Paolo Pellegrino ${ }^{1,2}$, Isabel Gràcia ${ }^{3}$, Carles Cané ${ }^{3}$, Sven Barth ${ }^{4}$ and Albert Romano-Rodríguez 1,2 \\ 1 Department of Electronic and Biomedical Engineering, Universitat de Barcelona (UB), \\ 08028 Barcelona, Spain; irminapeiro@hotmail.com (I.P.); elopez@el.ub.edu (E.L.-A.); \\ mmoreno@el.ub.edu (M.M.); ppellegrino@el.ub.edu (P.P.); aromano@el.ub.edu (A.R.-R.) \\ 2 Institute of Nanoscience and Nanotechnology (IN2UB), Universitat de Barcelona (UB), \\ 08028 Barcelona, Spain \\ 3 Institut de Microelectrònica de Barcelona-Centre Nacional de Microelectrònica, Consejo Superior de \\ Investigaciones Científicas (CSIC), 08193 Bellaterra, Spain; Isabel.Gracia@imb-cnm.csic.es (I.G.); \\ carles.cane@imb-cnm.csic.es (C.C.) \\ 4 Institute of Materials Chemistry, TU Wien, 1060 Vienna, Austria; sven.barth@tuwien.ac.at \\ * Correspondence: guillemdom@gmail.com; Tel.: +34-934034804 \\ + Presented at the Eurosensors 2018 Conference, Graz, Austria, 9-12 September 2018.
}

Published: 8 January 2019

\section{Summary}

Monoclinic gallium oxide $\left(\beta-\mathrm{Ga}_{2} \mathrm{O}_{3}\right)$ nanowires were fabricated via a metal-assisted vaporliquid-solid process using chemical vapor deposition techniques and carbothermal reduction. The fabricated nanowires were structurally and optically characterized, revealing a high crystalline nature, with strong photoluminescent emission and a bandgap of $4.2 \mathrm{eV}$. Using focused electron beam techniques, nanowires were individually contacted for their use as gas sensors. The fabricated devices were tested against different concentrations of gases up to temperatures of $200{ }^{\circ} \mathrm{C}$. Fast, stable and reproducible responses were measured towards water vapor at room temperature, with a power consumption in the $\mathrm{nW}$ range. The reaction promoting this response is strongly related to pre-adsorbed oxygen, a tight requirement for the water vapor sensing.

\section{Motivation and Results}

In the early nineties $\beta-\mathrm{Ga}_{2} \mathrm{O}_{3}$ appeared as an interesting material for high-temperature oxygen and reducing gases sensors in form of thin films [1]. As gallium oxide requires temperature above $600{ }^{\circ} \mathrm{C}$ to sense oxygen, several alternative strategies were explored to lower this threshold: surface functionalization with metal-particles, dopants or the use of morphologies with higher surface-tovolume ratio, like nanowires. The $\beta-\mathrm{Ga}_{2} \mathrm{O}_{3}$ nanostructure-based sensors have shown enhanced sensing performance when compared to thin film gas sensors, being able to sense reducing gases and volatile organic compounds at considerably low temperatures or even at room temperature with less power consumption than their thin film counterparts [2].

In this study, we present single $\beta-\mathrm{Ga}_{2} \mathrm{O}_{3}$ nanowire-based sensors, Figure $1 \mathrm{a}$, and their behavior when exposed to different concentrations of water vapor at room temperature, Figure $1 \mathrm{~b}$. The response measured increased with concentration and was always fast, between 7 and 2 min to reach a steady state when exposed from 40 to $80 \%$ of relative humidity, respectively. The maximum response lies around $97 \%$. With increasing temperature, the response decreased, disappearing at $\sim 150^{\circ} \mathrm{C}$. This occurrence seems to indicate that the sensing process is due to physisorption. 


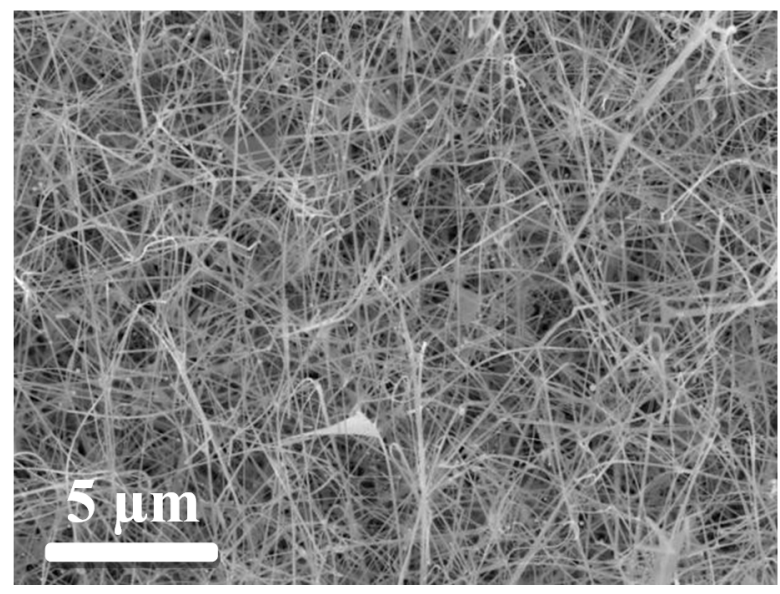

(a)

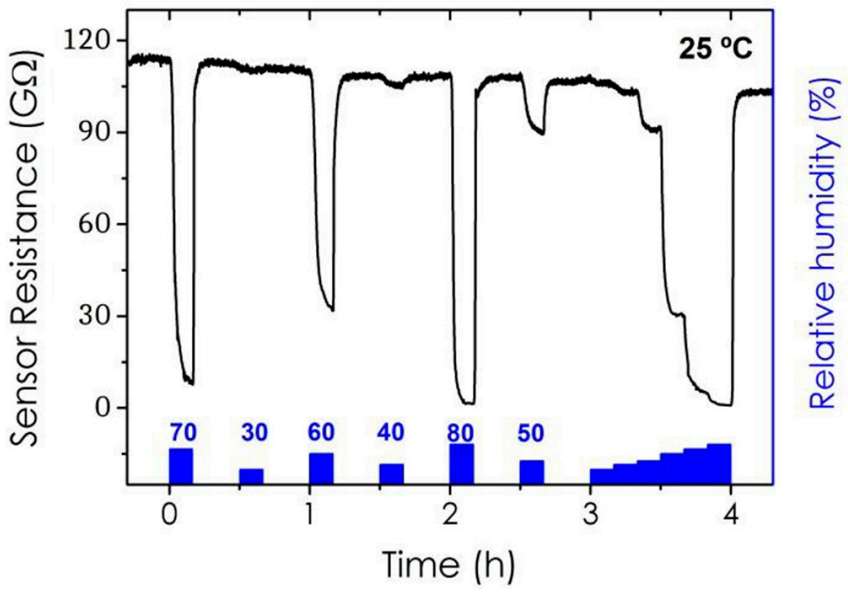

(b)

Figure 2. (a) Gallium oxide nanowires grown via gold-assisted vapor-liquid-solid process using chemical vapor deposition techniques and carbothermal reduction at $800{ }^{\circ} \mathrm{C}$; (b) Gallium oxide nanowire-based gas sensor's resistance evolution towards varying concentrations of relative humidity in synthetic air at room temperature.

To study possible reaction paths, tests were repeated under nitrogen ambient, revealing that water vapor promotes the oxygen desorption from the $\beta-\mathrm{Ga}_{2} \mathrm{O}_{3}$ nanowires and, therefore, the presence of oxygen at the surface or the surrounding of the sensing material is necessary for effective sensing. The oxygen adsorption on the surface of the nanowires was very fast, around 1 min for varying oxygen concentration.

\section{References}

1. Fleischer, M.; Meixner, H. Gallium oxide thin films: A new material for high-temperature oxygen sensors. Sens. Act. B Chem. 1991, 4, 437-441.

2. Park, S.; Kim, H.; Jin, C.; Lee, C. Synthesis, structure, and room-temperature gas sensing of multiplenetworked Pd-doped $\mathrm{Ga}_{2} \mathrm{O}_{3}$ nanowires. J. Korean Phys. Soc. 2012, 60, 1560-1564, doi:10.3938/jkps.60.1560. 